\section{Suffer the little children}

\author{
Stephen Hancocks OBE \\ Editor-in-Chief
}

It seems appropriate that as this issue is dated to arrive on the Easter weekend it should start with a biblical quote. In the case of the Gospel of Matthew chapter 19 verse 14, the context of 'Suffer the little children...' was to 'allow' or 'permit' children to approach Jesus. In the case of the research paper in this issue (Olley et al., online article E13) ${ }^{1}$ it is what we understand the word suffer to mean in one context in the 21st century: the extraction of teeth from children under general anaesthetic.

The debate over the reasons for not only the continuing, but quite shockingly the dramatic increase in the number of children admitted to hospital in England for the extraction of teeth due to caries encompasses many of the well known and well rehearsed arguments. Trying to get to grips with these various strands is, however, like trying to catch mercury; the fibres slip through the fingers and elude capture, denying anything approaching a comprehensive examination or logical and concerted forward planning. We are all weary of the phrase 'caries is a preventable disease'. In fact one has to question the pragmatic truth of that statement in the context of this matter. Adding the qualification that caries is in theory a preventable disease might be more realistic since we in the profession and we in the wider sense of public health and society continue to utterly fail to prevent it, sometimes seemingly almost wilfully.

\section{AS USEFUL AS BOBBY BUNNY}

We know, for example, that fluoridation of the water supply brings significant anti-caries benefits but we don't implement it. It is evidence-based. But we don't implement it. Instead we variously nod sagely at loose talk about mass-medication and acquiesce to the far less contentious but as yet evidence-baseless argument for improved oral health and dietary education for people whose children continue to 'eat sweets'. I thought that Davies and Bridgman in their opinion paper earlier this year hit the nail on the head with blinding clarity: "the days of puppet shows and colouring in of carrots have long gone'. What price a smiley Bobby Bunny earnestly saying 'don't eat sweets' as a 4-year-old wakes from a general anaesthetic with a mouth full of blood and a psychological scar that will be with her or him for a lifetime? But of course it is not that easy. Fluoridation is about the law, it is about budgets, it is about health authority boundaries, it is about water company jurisdictions, it is about rights and freedoms, it is about local accountability. To our screaming 4-year-old such complexities are as useful as Bobby Bunny.
We also know that caries can be treated. Correction; caries can in theory be treated. Again the argument has bounced backwards and forwards for years, in the columns of this journal and others. There are issues of co-operation from the child, access to care, remuneration, type of service agreement (capitation or fee-for-item of service), choice of materials. Once again, all very good points of debate, all valid factors but all too slippery to pin down for the benefit of the caries-suffering little person.

There is no doubt that caries is a socio-economically oriented condition, for despite the overall improvement in oral health in the UK in recent years there remain disadvantaged groups and individuals who have not benefited from the advances to anything like the same extent as the majority. Although not all parents were socially deprived in the current paper $^{1}$ this is reflected in the study population in various ways, including family size, access to care and repeat episodes of general anaesthesia for further reparative treatment or extractions. It is, as the authors state, a public health issue in general as well as an oral health issue. The current White Paper on public health in England, Healthy lives, healthy people, ${ }^{3}$ does include an objective to reduce the number of 5-year-olds with caries but, as the BDA's response states, ${ }^{4}$ this is somewhat light on detail. Perhaps this will come. Perhaps, we can learn from the ChildSmile programme in Scotland (http://www.child-smile.org.uk), or as Professor Welbury suggests in his Commentary on page 361, from the programmes in Denmark stretching back to the 1970s.

Professor Welbury also knows how to pack a punch, reminding us of the Hippocratic promise and suggesting that reducing the inequality of childhood caries is every parent and every adult's responsibility. Easter time, as well as being associated with chocolate eggs and other confectionery, is also a time for renewal and for looking ahead. Is there a chance that we can try and overcome all these sectionalised barriers and see the whole picture for once; a childhood caries Tsar perhaps? No one would wish the Easter Bunny (or Bobby Bunny for that matter) harm but let us similarly strive to eliminate suffering from the little children too.

1. Olley R C, Hosey M T, Renton T, Gallagher J. Why are children still having preventable extractions under general anaesthetic? A service evaluation of the views of parents of a high caries risk group of children. Br Dent J 2011; 210: E13.

2. Davies $\mathrm{G}$, Bridgman $\mathrm{C}$. Improving oral health amongst schoolchildren - which approach is best? Br Dent J 2011; 210: 59-61.

3. HM Government. Healthy lives, healthy people: our strategy for public health in England. London: The Stationery Office, 2010.

4. British Dental Association. Response to Healthy lives, healthy people: our strategy for public health in England. London: BDA, 2011.

DOI: $10.1038 /$ sj.bdj.2011.288 